\title{
Corneal degeneration in a congenitally diabetic inbred strain of mouse
}

\author{
L. H. HUANG AND T. W. SERY \\ From the Wills Eye Hospital Research Institute, Philadelphia
}

Heritable corneal degenerations in experimental animals have been reported infrequently: A few such reports by Loeffler (1932), Douglass and Russell (1947), and Mackensen ( I 96o) $\vec{\sigma}_{\mathscr{\sigma}}$ might possibly be considered as corneal degenerations but in the last two of these studieso. the condition was found in mutant mice which were born with their eyelids open, aif condition in which corneal damage will develop through exposure. Normally, the eyelids of newborn mice, such as the Swiss Webster strain, do not begin to open until the 1 2th day. Another instance of corneal degeneration in an inbred line of circling mice (Mus musculus) was described by Stein, Norvis, and Mason (1962), but they provided ${ }_{-}^{\circ}$ evidence that the abnormality is more likely to be a secondary reaction to degenerations beginning in the lens during embryonic development.

In humans, corneal dystrophies are inherited degenerations which tend to be bilateral $\overrightarrow{0}$ and progressive and have no known aetiology. Since the condition has a genetic origin it would be expected to be most readily found in inbred animals. Many such inbredర strains of animal now exist, but no corneal diseases have been reported which can bes related to one of the human forms of corneal degeneration or dystrophy. In the presento

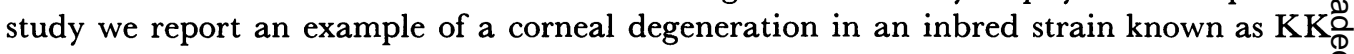
mice. Our experience with this example leads us to suspect that there may be other types of corneal disease in albino mice which have gone unnoticed because of the poor colouro contrast for corneal opacities and the small size of the eye. When such eyes are examined histologically or with an ophthalmoscope or slit lamp in vivo the corneal lesions are mosto readily recognized.

The inbred strain KK was first established by Kondo, Nojawa, Tomita, and Ejaki (1957) in Japan. Spontaneous diabetes mellitus was later discovered in this strain by Nakamura (I962) and confirmed by Tsuchida (1966). Nakamura's examination of $28 \mathrm{KK}$ miceo as compared to ten $\mathrm{C}_{57} \mathrm{~B}_{\mathrm{I}} / 6$ and five CBA mice showed that most of them yielded glucose tolerance curves similar to those of human diabetics. Control mice gave normal curves. $\bigcirc$ The majority of KK mice showed glycosuria with blood sugar levels exceeding $240 \mathrm{mg}$. I $00 \mathrm{ml}$. Histological findings in $\mathrm{KK}$ mice demonstrated degranulation of pancreatic $\beta$ cells, a deficiency of zinc content in islets, but no detectable change histochemically in ${ }^{\circ}$ insulin content. The livers had higher fat deposition and diminished glycogen content. N The adrenals were smaller than normal and the kidneys showed fibrosis. There were reduced thickness of the retina and cataractous changes in two 7-month-old mice. No mention was made of the condition of the cornea; Birnie, Pula, and Hammerle (1967) demonstrated elevated levels of immune reactive insulin in the pancreas in contrast too Nakamura's findings. Treser, Oppermann, Ehrenreich, Lange, Levine, and Camerini-o Davalos (1968) demonstrated glomerular lesions in non-obese KK mice similar to those found in humans. Of $39 \mathrm{KK}$ mice 60 per cent. showed early glomerular sclerosis with?

Received for publication April 20, 1970 Address for reprints: Dr. T. W. Sery, Ph.D., Wills Eye Hospital and Research Institute, r6or Spring Garden Street, Philadelphiaß Pa., 19130, U.S.A. This investigation was supported in part by Public Health Service Research Grant FR o55 ro from the General Research Support
Division, by Smith Kline and French Laboratories, Philadelphia, Pa., and by PHS Research Grant No. EY oor 95 from the NationaL Eye Institute 
segmental thickening of the capillary walls and basement membranes, frequently associated with exudative nodular lesions. More recently, in our laboratory, Kaczurowski (1970) used a special flat preparation of the retina with silver staining to demonstrate the presence of microaneurysms in the retinal vasculature of $\mathrm{KK}$ mice.

In this report we present statistical and histological evidence that a corneal degeneration exists as a hereditary malformation in $\mathrm{KK}$ mice beginning very early in life and becoming progressively worse with age.

\section{Materials and methods}

KK mice were obtained from the animal colony of the Smith Kline and French Laboratories, Philadelphia. Normal Swiss Webster mice were used as controls. An initial group of $22 \mathrm{KK}$ mice of both sexes was obtained with an age variation of $\mathrm{I}$ to 7 months. The ages of subsequent acquisitions of over 100 mice were 7 to 24 months. Mice were maintained on a diet of Purina laboratory chow and water ad libitum.

Randomly selected mice were examined for evidence of diabetes mellitus by running a glucose tolerance blood sugar curve on blood from the tail vein. All examinations of the eyes were made in vivo with a Haag-Streit slit lamp and an ophthalmoscope.

For histology, the mice were killed by the injection of an overdose of Nembutal. The eyes were fixed in to per cent. buffered neutral formalin and sections were stained with haematoxylin and eosin for routine staining, von Kossa's stain and alizarin red for calcium deposits, periodic acid Schiff for mucopolysaccharides, and Sudan black for lipids. Special procedures were followed to avoid the extraction of lipids in routine histology.

\section{Results}

GENERAL GHARACTERISTICS

KK mice are moderately obese, have ruffled fur (Fig. I), and are sluggish in their movements.

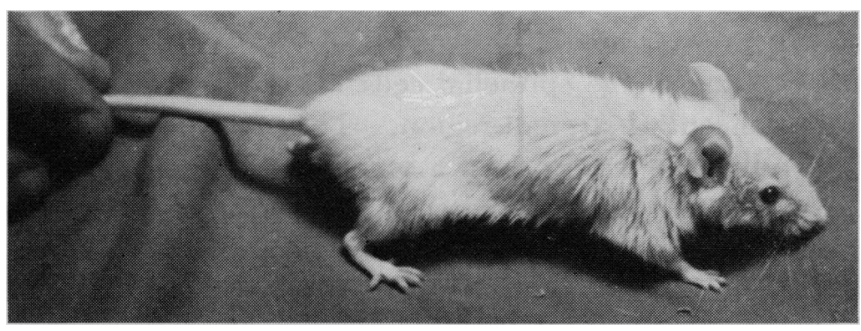

FIG. I KK mouse (I year old)

They are born with closed eyelids which do not begin to open until the 2 Ist day. Mice with advanced corneal lesions are blind because the opacity is always centrally located. The lesions begin within the first 2 months of life as small opacities less than $0.5 \mathrm{~mm}$. in diameter. With age the opacities extend into the anterior stroma and grow laterally. After 6 months the lesions are bilateral in most cases.

When examined with the ophthalmoscope or slit lamp, these lesions resemble an aggregate of bubble-like cysts forming geometric or irregular geographic map-shaped opacities. They are located in the stroma in the central area, are refractile, and have a metallic or diamond-like lustre (Figs 2 and 3, overleaf). The corneal surface is thicker or elevated in the area of the lesion. Older advanced lesions tend to become vascularized (Fig. 3). When the lesions extend laterally, islands of bubble-like cysts will develop into tiny clusters. The corneal tissue between them is normal, but in time the whole region coalesces into one or more large degenerative areas. Corneal lesions were not found at the periphery. 


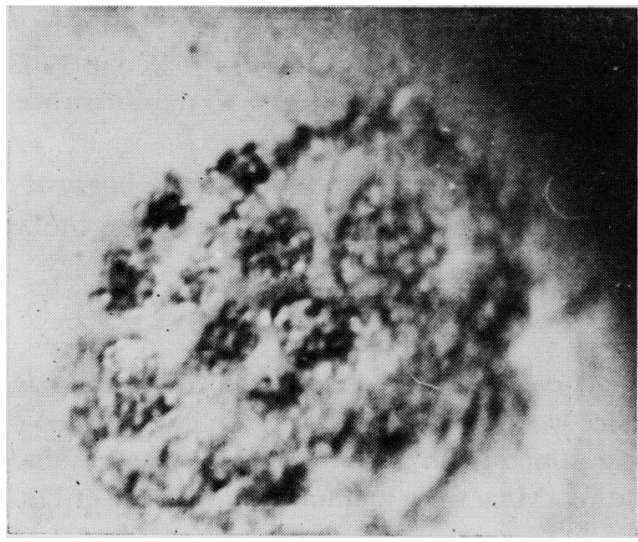

FIG. 2 As seen through a slit lamp the corneal lesion in a mature $K K$ mouse eyz has a large central opacity. The general appearance presents a type of crystalline granularity or bubble-like clusters. The lesion is irregular in shape and uneven in its topography. The corneal periphery shows no detectable pathology. Photographed through a specially modified Haag-Streit slit lamp, Pan X film, 3 sec. exposure at 7.5 volts. $\times 170$

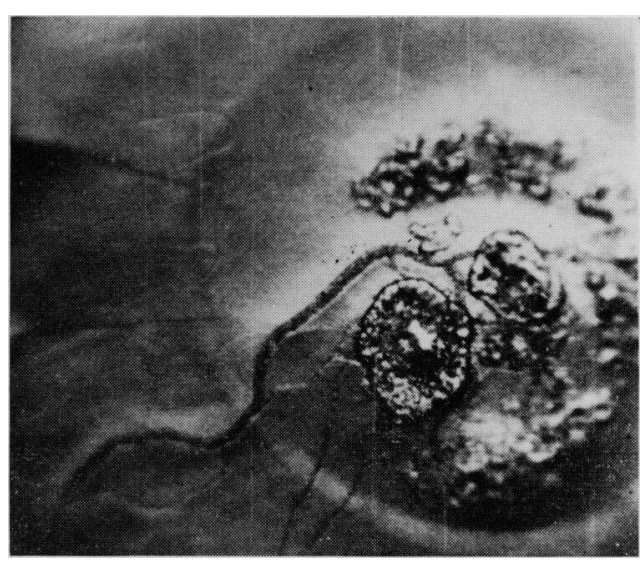

FIG. 3 Corneal degeneration with neovasculariza- of tion. The vessels in older lesions extend wall into the centre of the lesion. Photographed as in Fig. 2. N $\times 170$

Of the 44 corneae observed in $\mathrm{KK}$ mice aged $\mathrm{I}$ to 7 months which had established diabetic glucose tolerance curves, $4^{\mathrm{I}}$ had central corneal degeneration. None of the twenty corneae in normal Swiss Webster mice had any defect. The incidence of corneal opacities in over Ioo KK mice 6 to 18 months old was 75 per cent.

HISTOPATHOLOGICAL EXAMINATION
The lesions begin with swelling of the epithelial cells. In older mice they extend to the anterior and finally into the central stromal region. They then occupy about half of the stromal thickness. The advanced lesions show a separation of the lamellae of the stroma with open or empty spaces. A hyalin-like material is infrequently present between these $\frac{\partial}{0}$. lamellae in sections stained with haematoxylin and eosin (Figs 4 and 5). No lipid- $\frac{5}{3}$ staining material was found in the lesions. A membrane-like material is present in small segments along the inner surfaces of the empty spaces (Figs 4 and 6).

Histological preparations with alizarin red and von Kossa's stain gave pronounced $\circ$ calcium reactions in the region of corneal degeneration (Fig. 7).

Vascularization of older lesions is present in some eyes (Fig. 4). There is an active but minimal cellular response in these lesions in which polymorphonuclear and mono- N nuclear leucocytes may be seen in small numbers. The epithelium may heal leaving no N scar. The posterior stroma, Descemet's membrane, endothelium, and peripheral areas $\underset{\omega}{\mathcal{E}}$ of the cornea were unaffected by the severe central lesions.

\section{Comment}

The observations in this preliminary study suggest that an inherited degenerative process exists in the $\mathrm{KK}$ mouse cornea. The lesion occurs in a high percentage of randomly selected KK mice, is almost entirely bilateral, and has an early onset. The corneal $\mathbb{\mathbb { D }}$ lesions are light grey opacities. In a pigmented mouse such a defect would be easily $\underset{\mathbb{Q}}{\mathbb{Q}}$ visible to the unaided eye because of the strong contrast of the grey opacity against a dark 


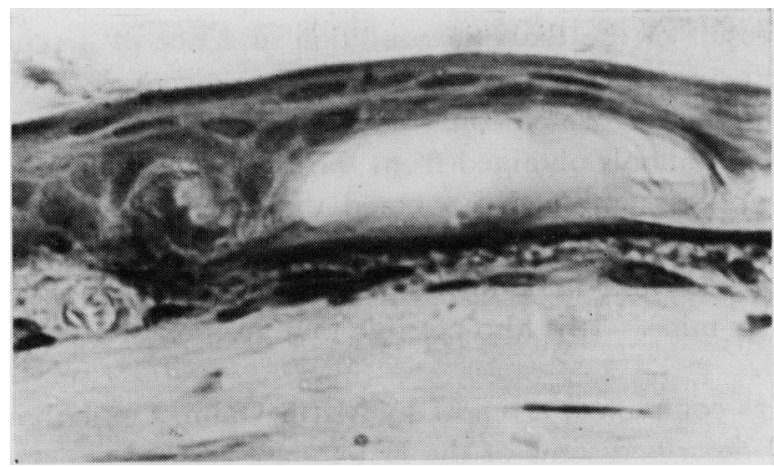

FIG. $4 K K$ mouse corneal degeneration. Note large vacuole in disorganized epithelial layer and a membrane-like deposition at its base. Both the epithelial and stromal layers are somewhat thickened. Haematoxylin and eosin. $\times 405$
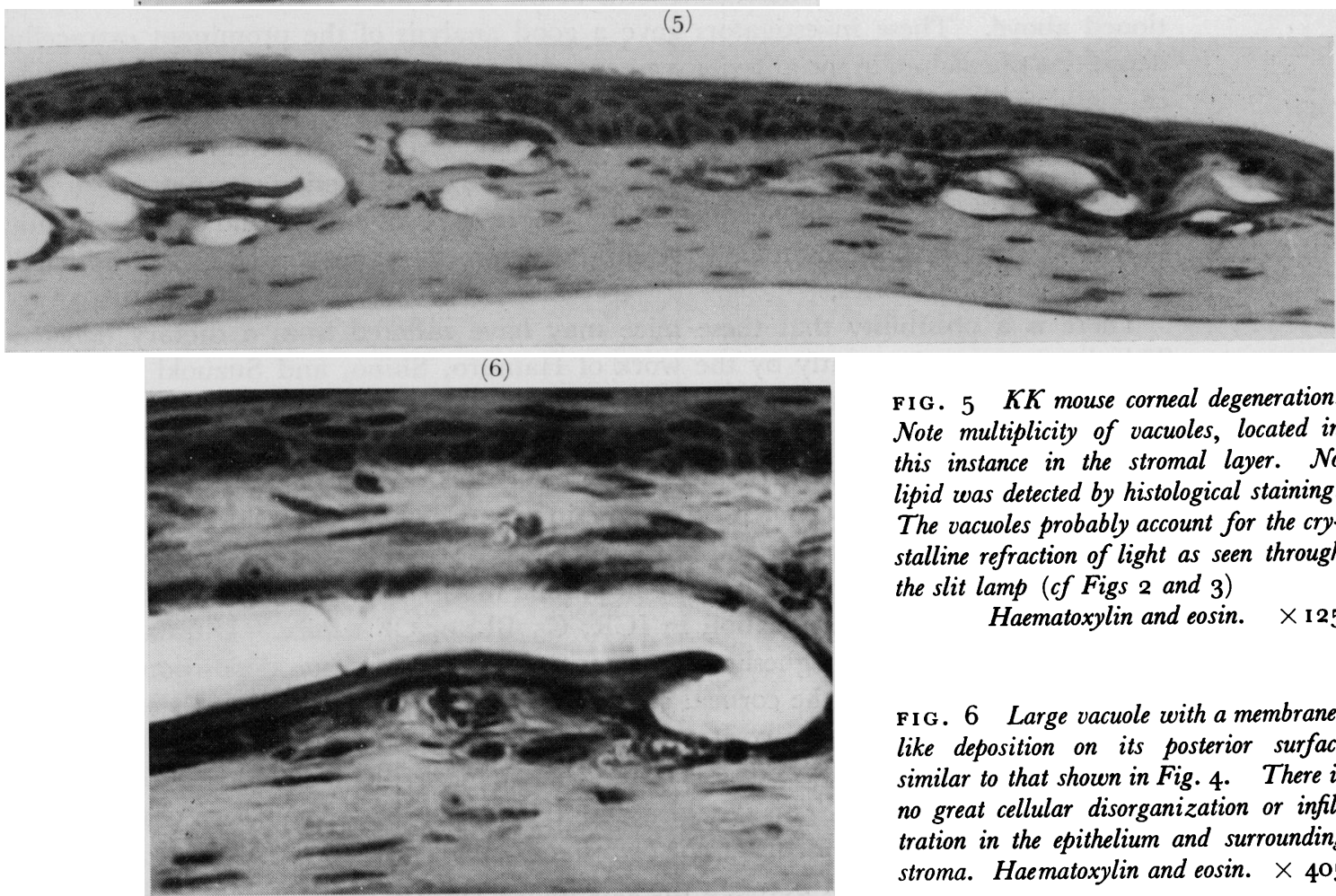

FIG. $5 K K$ mouse corneal degeneration. Note multiplicity of vacuoles, located in this instance in the stromal layer. No lipid was detected by histological staining. The vacuoles probably account for the crystalline refraction of light as seen through the slit lamp (cf Figs 2 and 3)

Haematoxylin and eosin. $\times 125$

FIG. 6 Large vacuole with a membranelike deposition on its posterior surface similar to that shown in Fig. 4. There is no great cellular disorganization or infiltration in the epithelium and surrounding stroma. Haematoxylin and eosin. $\times 405$

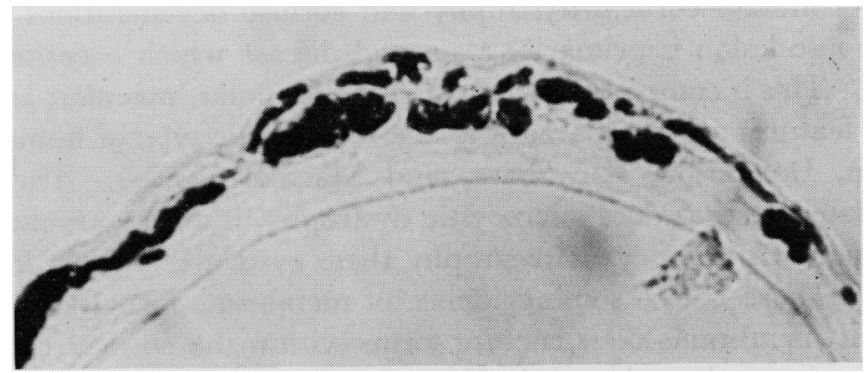

FIG. $7 K K$ mouse corneal lesions with massive accumulations of calcium-containing deposits. Calcium was detected in every preparation by alizarin red and the von Kossa stain. Alizarin red stain. $\times 94$

background. In albino $\mathrm{KK}$ mice, the condition is imperceptible on casual observation. This might explain why the many investigators working with $\mathrm{KK}$ mice have failed to report the condition for over 13 years. Another possible explanation is that the corneal 
lesion may be a natural result of the diabetic condition and not of a separate genetice defect. It would then be expected that some mice with less severe diabetes would form fewer corneal defects or mild defects which could be missed even biomicroscopically. In $\underline{\underline{\Xi}}$ some of the latter groups of animals obtained from the SKF laboratories early in 1969 : when their colony was being discontinued, we noted that there was an unusually low? incidence of corneal defects. In some groups of $\mathrm{KK}$ mice corneal degenerations were found in only 25 per cent. rather than in 90 to roo per cent. No glucose tolerance curves were obtained on these later mice. It is also possible that accidental cross-breeding with $\mathbb{B}$ normal mice had occurred.

After this manuscript was completed, a report by Mittl, Galin, Opperman, CameriniDavalos, and Spiro (1970) described some of the KK mouse corneal abnormalities men: tioned above. These investigators gave a good analysis of the prominent extracellular deposition of calcium in the anterior segment of the cornea. They also provided histologi흥. cal evidence that the calcium deposits occurred as carbonate and/or phosphate compoundsig When they found that serum calcium and phosphate levels were not elevated in KK mices as compared to normal mice, they suggested that the corneal lesion was not due to hyperĩ calcaemia. The clinical and histological findings in their laboratory and ours are identical 0 It is interesting that the animals were supplied from the same source-the Smith Kline and French Laboratories.

There is a possibility that these mice may have suffered from a dietary deficiency This was suggested recently by the work of Hamuro, Shino, and Suzuoki (1970), who found that $\mathrm{KK}$ mice developed calcium deposits in the heart muscle when maintained on a stock diet. By manipulating dietary magnesium and phosphorus in purified diets: they were able to augment or completely prevent this tissue calcium deposition. Whens KK mice were fed diets deficient in magnesium and high in phosphorus, both the hear and kidney were severely affected with high levels of tissue calcium. They found this effect to be associated with a rapid rise in plasma inorganic phosphorus. The same diets did not produce tissue calcification in ICR, $\mathrm{C}_{57} \mathrm{BL}$, or $\mathrm{CF}$ I mice. Ultimately they fele that a diet deficient in magnesium was responsible for the tissue deposition of calcium No mention was made of the corneal condition but this could easily have been overlooked. as mentioned above. If the corneal defect we have observed was caused by a lack of̂. dietary magnesium, then it is possible that a change in the diet could have occurred duringo the course of our study. This would account for variations in the percentage of ocular. defects in subsequent shipments of our own mice. This possibility will be studied.

Certain similarities exist between the KK mouse corneal degeneration and some of the classic descriptions of human corneal dystrophy and corneal degenerations (Duke-Elder? 1965). The KK mouse lesion is primarily a stromal disease which occasionally extends into the epithelium. This is comparable to some of the granular, macular, and crystalline dystrophies. Some features are comparable to the microcystic type of human dystrophy described by Cogan, Donaldson, Kuwabara, and Marshall (1964). The KK mouse disease forms vacuolated cysts as does microcystic dystrophy, but they are most often seen $\omega$ in the corneal stroma. In microcystic dystrophy these cysts are entirely located in the corneal epithelium. There is also some evidence of membrane formation in the mouse cornea. A basement membrane-like structure forms within the corneal epithelial laye in human microcystic dystrophy, whereas in $\mathrm{KK}$ mice the laying down of membrane-liked material occurs in the lining of the vacuolated cysts in the stroma. In human cornea macular dystrophy the lesions are distributed over the whole cornea. This was not the case in any of the KK mice, in which the lesions were entirely central. In human granular 
dystrophy, the lesions are located centrally but the tissue between the granular degenerations is normal and clear. In the $\mathrm{KK}$ mice there is no granular distribution and the involved area tends to be continuous. In some of the younger animals, however, there are degenerative plaques separated by clear corneal tissue.

The finding of abnormal amounts of calcium in $\mathrm{KK}$ mouse corneal lesions provides the first clue to the cause of the tissue damage. The primary questions are:

(I) Is the KK corneal degeneration directly attributable to the diabetic condition?

(2) Is it related or unrelated to the diabetic abnormality through a nutritional deficiency?

(3) Is it a separate genetic disorder?

The KK mouse provides the first experimental model of a heritable corneal degeneration which mimics many of the clinical characteristics of human corneal dystrophies.

\section{Summary}

A corneal degeneration has been described in an inbred mouse line, the $\mathrm{KK}$ congenitally diabetic strain. The lesion begins in early life, is progressive with age, tends to be bilateral, and is confined mainly to the anterior part of the corneal centre. The lesions appear to be due to an inherited degeneration, but it is not known if they are the result of diabetes or of a separate genetic aberration. The condition is not due to exposure trauma such as that found in mutant mice which are born with slit lids or open eyelids. Histological study has revealed the presence of abundant calcium in the corneal lesions. Recent findings of tissue calcium deposition in the $\mathrm{KK}$ mouse heart and kidney after deficient dietary magnesium suggest that the corneal damage demonstrated in this study may also be related to dietary magnesium deficiency and raised dietary phosphorus in diabetic KK mice. The availability of an animal model with one form of corneal degeneration will provide ready access to viable tissues for biochemical and histopathological studies.

The authors are grateful to Dr. James Birnie of Smith Kline and French Laboratories for his advice, assistance, and encouragement in this study. We also wish to thank him and Smith Kline and French Laboratories for supplying us with $\mathrm{KK}$ and normal mice and for performing the pharmacological tests on these animals, and Mrs. Addie Wilson for the histological preparations.

\section{References}

BIRnie, J. H., PUla, P., and hammerle, P. (1967) Physiologist, ro, 125

Cogan, D. G., Donaldson, D. D., KuWABara, T., and marshall, D. (ig64) Trans. Amer. ophthal. Soc.,

62, 2 I 3

Douglas, P., and Russell, w. L. (1947) Anat. Rec., 97, 4 I 4

DUKe-ELDER, S., and LeIGH, A. G. (1965) "System of Ophthalmology", vol. 8. "Diseases of the

Outer Eye", part 2, "Cornea and Sclera". Kimpton, London.

hamuro, y., shino, A., and suzuoki, z. (i970) J. Nutr., roo, 404

kAczurowski, м. (1970) Arch. Ophthal. (Chicago), 84, 3 I 6

kondo, к., Nojawa, к., томita, т., and ejaki, E. (1957) Bull. exp. Animals (Tokyo), 6, 107

LOEFfler, L. (1932) Z. indukt. Abstam. u. Vererbungslehre, 6r, 409

MACKENSEN, J. A. (ig6o) J. Hered., 51, I 88

MitTl, R., GALIN, M. A., OPPERMAN, W., CAMERINI-DAVAlos, R. A., and SPIRo, D. (I970) Invest. Ophthal.,

9, 137

nakamura, м. (ig62) Proc. Japan Acad., 38, 348

Stein, K. F., NORRIS, B. E., and mason, J. (1967) Develop. Biol., r6, 315

TRESER, G., OPPERMANN, W., EHRENREICH, T., LANGE, K., LEVINE, R., and GAMERINI-DAVALOS, R. A.

(1968) Proc. Soc. exp. Biol. (N.Y.), 129, 820

TsuchidA, I. ( 1966) Japan diabet. Soc., 9, 67 